\title{
A PROPOSTA DE DAVIDE NICOLINI PARA UMA ABORDAGEM DA PRÁTICA: A BASE PARA UMA TEORIA FUNDAMENTADA
}

\author{
S. VOGT ${ }^{1}$, Y. L. M. BULGACOV ${ }^{2}$, J. S. VILELA ${ }^{3}$, C. J. A. CHAVES ${ }^{4}$ \\ Universidade Positivo ${ }^{1,2,3}$ \\ Universidade Estadual de Mato Grosso do Sul ${ }^{4}$, \\ sergiovogt@gmail.com ${ }^{1}$; jaelso.chaves@hotmail.com ${ }^{4}$
}

Artigo submetido em 19/12/2018 e aceito em 18/12/2019

DOI: $10.15628 /$ holos.2019.8087

\section{RESUMO}

Este ensaio busca contribuir para a compreensão da proposta de Nicolini sobre a abordagem das práticas, tendo como foco principal o seu livro "Practice Theory, Work, and Organization" (2012). Para tanto, foi apresentada a seguinte questão: Qual é a proposta de Davide Nicolini? Destaca-se que Nicolini não está interessado em propor uma nova teoria da prática, pois sua proposta fornece uma pluralidade de conceitos sensibilizadores pertencentes a ontologias, epistemologias e metodologias distintas que apresentam semelhanças entre si formando um "ecletismo programático". Percebe-se que o autor fornece as bases e orientações para uma teoria fundamentada que possa vir a ser construída a partir da prática, do empírico, mantendo-se, assim, coerente com o ethos, com a lógica da "prática", rompendo com as dicotomias das abordagens tradicionais, constituindo uma ontologia plana e relacional. Nesse sentido, este trabalho enfatiza a Grounded Theory como uma possibilidade metodológica a ser utilizada no estudo das práticas.

PALAVRAS-CHAVE: Abordagem da Prática, Teorias da Prática, Ecletismo Programático, Grounded Theory.

\section{DAVIDE NICOLINI'S PROPOSAL FOR A PRACTICE APPROACH: BASIS FOR A GROUNDED THEORY}

\begin{abstract}
This essay seeks to contribute to the understanding of Nicolini's proposal on the approach to practices, focusing mainly on his book "Practice Theory, Work, and Organization" (2012). To that end, the following question was presented: What is Davide Nicolini's proposal? It should be noted that Nicolini is not interested in proposing a new theory of practice since his proposal provides a plurality of sensitizing concepts belonging to different ontologies, epistemologies and methodologies
\end{abstract}

that have similarities between them forming a "programmatic eclecticism". It is perceived that the author provides the bases and orientations for a theory founded that can be constructed from the practical, from the empirical, thus remaining coherent with the ethos, with the logic of "practice", breaking with the dichotomies of traditional approaches, constituting a flat and relational ontology. In this sense, this work emphasizes Grounded Theory as a methodological possibility to be used in the study of practices.

KEYWORDS: Practice Approach, Theories of Practice, Programmatic Eclecticism, Grounded Theory. 


\section{INTRODUÇÃO}

Neste ensaio teórico, pretende-se contribuir para a compreensão da proposta de estudos de Nicolini (2012) sobre a abordagem da prática em seu livro "Practice Theory, Work, and Organization", bem como problematizar suas implicações para a construção de um tipo de "teoria social". Nesta introdução, propõe-se esclarecer e problematizar a premissa de Nicolini de uma abordagem da prática.

O autor parte da premissa de que a abordagem da prática é uma ruptura radical com as formas de compreender as questões sociais e organizacionais, oferecendo alternativas para as ciências sociais. Assim, Nicolini introduz, baseado em Schatzki (2002), o que chama de "o retorno da prática". Acredita que o estabelecimento de prática, enquanto unidade de análise para o estudo da organização, pode contribuir com a teoria das organizações que, segundo ele, tornou-se

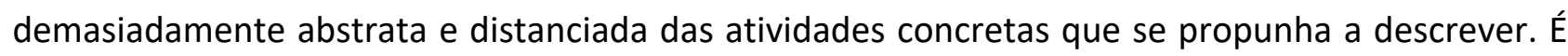
nesse sentido que se questiona: Em que medida Nicolini consegue resolver a proposta de distanciamento de uma teoria abstrata?

Na introdução de seu livro, Nicolini propõe-se a responder algumas questões que delineiam o campo de estudo das práticas: O que é a teoria da prática? Existe apenas uma ou são várias as teorias da prática? Quais suas origens? O que dizem? Elas realmente têm algo novo para oferecer para os estudos organizacionais?

Um dos esclarecimentos a se realizar diz respeito à diversidade de denominações que são utilizadas quando se refere ao estudo das práticas. Prática é um termo de uso comum, propiciando ainda mais indefinição do seu significado. Ao longo de toda obra, são utilizados vários termos: "Teorias da prática", "Abordagem da prática", "Linguagem da prática”, "Lente da prática", "Idioma da prática". É nessa multiplicidade de nomenclaturas também que reside a complexidade do campo e a amplitude das diferentes formas de se estudar o fenômeno em questão: a(s) prática(s). Ou seja, como Nicolini, ao longo de sua obra, tenta resolver a questão da multiplicidade de conceitos sobre a prática?

$\mathrm{Na}$ primeira parte do livro, o autor propõe uma visão geral das teorias da prática contemporâneas. Ao longo da obra, ilustra como elas podem contribuir para a compreensão das organizações e de outros fenômenos sociais. São apresentadas diferentes formas de teorizar a prática, pois "muito se ganha em usar essas abordagens em combinação em vez de tentar uma grande síntese" (NICOLINI, 2012, p. 9). É nesse sentido que surgem também alguns questionamentos que norteiam este trabalho, tais como: O que significa usar essas abordagens em combinação? Não teriam bases específicas tanto do ponto de vista ontológico, epistemológico e metodológico? Estaria Nicolini sendo incoerente na sua proposta de construção do conhecimento?

Dessa forma, caminhando em direção à compreensão da proposta do autor, surgem outros questionamentos que, uma vez respondidos, também podem contribuir com o objetivo proposto por este trabalho: Qual a promessa de Nicolini quando se refere a uma Abordagem da Prática? 0 que significa sua proposta denominada por "ecletismo programático"? O que significa trazer essa 
multiplicidade de elementos teóricos distintos que, segundo o autor, devem ser estudados de forma conjunta?

Nesse sentido, este ensaio estrutura-se inicialmente em: esclarecer os rompimentos que Nicolini pretende fazer em relação às teorizações clássicas nos estudos organizacionais; apresentar uma proposta da construção de conhecimento, explicitando suas bases ontológicas, epistemológicas e metodológicas; revelar as características dessa proposta de construção do conhecimento; sugerir o emprego da Grounded Theory como um recurso metodológico a ser empregado de forma conjunta no estudo das práticas e, por fim, as considerações finais, que sintetizam os argumentos desenvolvidos ao longo do artigo.

\section{DISCUSSÃO TEÓRICA}

2.1 Uma proposta de rompimento com as "Velhas Formas Insustentáveis de Teorizações" das organizações

Para Nicolini, a abordagem baseada na prática é uma alternativa às perspectivas cognitivistas que tentam explicar a organização como fenômenos decorrentes do cérebro e da mente dos indivíduos, como processo mental intangível, forma de troca simbólica ou um processo abstrato de coordenação com base em algum tipo de processo comunicativo (WEICK, 1979; HUTCHINS, 1995). A abordagem baseada na prática considera a cognição e o sensemaking como emergindo das práticas que constituem a organização. Sensemaking e conhecimento estão localizados na atividade material e discursiva, no corpo, nos artefatos, nos hábitos e nas preocupações que permeiam a vida dos membros da organização (NICOLINI, 2012).

O discurso como prática também se mantém longe de visões que compreendem as questões sociais como meras trocas simbólicas entre seres humanos (como a tradição do interacionismo simbólico), ou que sugerem que o mundo é trazido à existência por meio de sinais, textos e processos semióticos como nas formas modernas de textualismo. A linguagem focaliza a explicação do fenômeno social de forma processual, sem perder de vista a natureza mundana da vida cotidiana e da natureza concreta e material das atividades com as quais estamos todos envolvidos (NICOLINI, 2012).

Em seu livro, Nicolini (2012) também se afasta de teorias funcionalistas que conceituam a organização como sistemas voltados para resultados, afirmando ter como objetivo abandonar "velhas formas insustentáveis de teorizações" (p. 3). Segundo o autor, nas últimas três décadas, o exame das organizações como entidades (coisas) ou como discursos teóricos tem migrado para o estudo das organizações como um processo social, o que se acredita, tem criado um terreno fértil para as teorias da prática, especialmente por sua capacidade de fornecer uma visão processual das questões organizacionais e colocar em primeiro plano o papel central das atividades humanas, como por exemplo, no trabalho de Souza e Fenili (2016), no qual os autores propõem o estudo da cultura organizacional por meio das práticas.

Assim sendo, Nicolini (2012) ressalta que as teorias da prática são inerentemente relacionais e veem o mundo como um conjunto contínuo, com nexos (os quais Hui, Schatzki e Shove (2017) 
sugerem que sejam analisados) e de alianças de práticas. Tenta-se, igualmente, romper com teorias que comportam dualidades, pois se aponta também como vantagem que uma visão do social (baseada na prática) possibilita dissolver (e não resolver) os dualismos entre ator/sistema, social/material, corpo/mente e teoria/ação.

\subsection{Uma proposta para o estudo da prática}

Na primeira parte de seu livro, Nicolini (2012) oferece uma visão geral das "teorias da prática" contemporâneas, ilustrando como podem contribuir para a compreensão das organizações e de outros fenômenos sociais. Teorias como a de Bourdieu ${ }^{1}$, Wittgeinstein, Heiddger, Marx, que, embora não sejam conhecidas como "Teorias da Prática", são assim denominadas, uma vez que trazem concepções de prática que serão apropriadas em sua proposta de estudo da prática. A partir desse resgate, o autor nomina a sua proposta de estudo da prática como: "Abordagem da prática".

Fica evidente a sua posição de não se comprometer em introduzir uma teoria da prática. Ele afirma, literalmente, que "não estou interessado em propor uma nova teoria da prática" (NICOLINI, 2012, p. 213), mas sim uma "cartilha da prática". Assegura que utiliza as diferentes teorias de distintas abordagens para extrair conceitos sensibilizadores para construir um "kit ferramentas". Afirma que "muito se ganha em usar estas abordagens em combinação" (NICOLINI, 2012, p. 9). A sua abordagem da prática está enraizada em diferentes tradições de pensamento, conforme argumenta, "se constituem em uma ampla família conectada por uma teia de semelhanças" (NICOLINI; MONTEIRO, 2017, p. 3).

Nicolini atribui duas razões para se abordar as teorias como pluralidade, como uma forma programática de ecletismo². A primeira é uma razão tática, dado que cada uma das abordagens discutidas tem vantagens e limitações. Outra razão, considerada por Nicolini como sendo a estratégica, tem a ver menos com o trabalho empírico e mais com a questão do que é a "boa ciência social", a qual, afirma, torna-nos mais articulados e capazes de perceber as diferenças que compõem o universo complexo e multifacetado em que vivemos e que(se) reflete também o(no) contexto organizacional. Essa "boa ciência" proporciona-nos uma compreensão mais rica e mais cheia de nuances do mundo, e não apenas respostas simplificadas. A boa ciência é generativa e não eliminativista: seu objetivo é aumentar a nossa capacidade de fazer conexões entre os fenômenos, não é erradicar características interessantes em nome de generalizações (NICOLINI, 2012, p. 215). Assim, decorrente dessas "diferentes", mas "semelhantes" teorizações, o autor extraiu o que denominou de conceitos sensibilizadores que, em sua opinião, equivalem a ser coerente com o ethos (ou seja, o conjunto daquilo que define uma determinada comunidade), com as abordagens da prática que se esforçam para tornar o mundo mais rico em significado.

É preciso familiarizar-se com as diferentes tradições que constituem os "afluentes" para o "grande mar" das teorias da prática (NICOLINI, 2012, p. 10). Por essa razão, a sua proposta fornece-

\footnotetext{
${ }^{1}$ Base teórica que compõe a proposta de estudo das práticas sugerida por Souza e Fenili (2016).

2 O ecletismo programático proposto por Nicolini é uma "modesta tentativa", segundo o autor, de aderir a esses cânones da "boa ciência" contra o risco do eliminativismo que se esconde também entre alguns teóricos da prática (NICOLINI, 2012, p. 216).
} 
nos um indicativo inicial de várias abordagens diferentes. Segundo o autor, existe uma oportunidade de usar algumas dessas abordagens em combinação. Ele acredita que todas as teorias da prática (pelo menos as que foram pesquisadas) são ligadas por uma complexa rede de semelhanças. Dessa forma, essas teorias podem ser mobilizadas em conjunto para enriquecer nosso entendimento da(s) prática(s) e fornecer uma compreensão baseada na prática de todos os aspectos sociais e organizacionais. Destaca ainda que colocá-las juntas não significa tentar unificá-las. Pelo contrário, a ideia é explorar tanto as suas semelhanças quanto suas diferenças, seguindo o que fora chamado de abordagem toolkit (NICOLINI, 2012).

Considerada essa tomada de posição "eclética" de Nicolini é que se pergunta: em que medida não incorre em uma proposta (para o estudo da prática) de construção de conhecimento incoerente, não respeitando as bases ontológicas, epistemológicas e metodológicas? Nesse sentido, há uma preocupação explícita do autor, que destaca que essa construção de conhecimento sobre a prática requer uma familiarização não só com o acervo de conceitos oriundos de diferentes teorias, mas também com seus pressupostos, para que não se acabe por usar teorias que se contradigam. Ou seja, deve haver um comprometimento, de uma forma ou de outra, com uma ontologia baseada na prática, a coerência tem que prevalecer. Dessa forma, procura-se, a seguir, elucidar o que se acredita ser uma proposta coerente de construção do conhecimento, sendo próprio de uma teoria fundamentada explicitar sua concepção ontológica, epistemológica e metodológica.

\subsection{Base Ontológica}

Para Nicolini, a linguagem da prática, ou o idioma da prática, como muitas vezes nomina, seria uma escolha ontológica, um reconhecimento da primazia da prática nas questões sociais, bem como a adoção da ideia de que elas, de uma forma ou de outra, são fundamentais para a produção, reprodução e transformação das questões sociais e organizacionais. Llewellyn (2008) entende que as práticas da realidade organizacional, bem como dos fenômenos sociais, poderiam ser estudadas não somente de forma descritiva, mas também explicativa. É por isso que Nicolini afirma que as teorias da prática são complementares (alternativas) a todas variantes do realismo (tanto ingênuo como crítico) e perguntam como as características aparentes de nosso mundo cotidiano, as quais os realistas e os realistas críticos acreditam, são trazidas à existência (NICOLINI, 2012).

A fim de justificar as conexões entre conceitos (os quais ele irá, posteriormente, utilizar para constituir os conceitos sensibilizadores) de diferentes autores, tais como Bourdieu, Giddens, Fairclough, Latour, Schatzki, Gherardi, Czarniawska, Wittgenstein, Marx, Heidegger e outros, Nicolini apresenta a proposta de uma ontologia plana como uma forma de acessar os diversos conceitos que estão inseridos na rede de conexões das (diferentes) teorias da prática. Mas, o que significa essa ontologia plana?

Uma vez que uma das características comuns das abordagens das práticas é a crença de que as atividades humanas são concretas, uma ontologia plana, conforme afirma Nicolini (2017), não faz distinção entre níveis (micro e macro). Teóricos da prática que adotam uma ontologia plana e juntam forças com outras sociologias relacionais sugerem que todos os fenômenos sociais, de pequena e grande escala, são constituídos e experienciados em termos de "micro" (práticas) situações (EMIRBAYER, 1997). Nessa perspectiva, assume-se que "fenômenos de grande escala" são 
"constituídos por meio da agregação de práticas inter-relacionadas e seus regimes de reprodução" (NICOLINI, 2017, p. 3). Para Nicolini, baseado em Emirbaye (1997) e em Latour (2005), o "macro" sempre se resume em práticas concretas. Por conseguinte, nosso entendimento é de que as dimensões "macro" são mediações das atividades concretas do mundo em que vivemos.

\subsection{Base Epistemológica}

Como comentado, Nicolini afasta-se de uma base epistemológica positivista e funcionalista de pensar as organizações ${ }^{3}$. Para ele, as teorizações são um esforço performativo da construção do mundo e a reconfiguração da realidade (NICOLINI, 2012). Isso significa que para gerar um mundo (social) feito de práticas, um conjunto de teorias não é suficiente. O que seria necessário, de fato, é um pacote prático coerente de teoria e método. Ou seja, a ideia de uma teoria da prática sem corpo estaria em contradição com o pressuposto básico e o projeto ontológico da abordagem. Dessa forma, na medida em que o mundo em que vivemos é feito de práticas, teoria só pode ser concebida como uma forma de prática (NICOLINI, 2012).

Assim, o autor chama a sua abordagem de um "pacote de ferramentas" (toolkit). O ponto de partida proposto no pacote teórico-metodológico é a utilização de um conjunto de conceitos sensibilizadores (ou seja, questões) que convidam para que se realizem dois movimentos básicos: o zoom in sobre as práticas e o zoom out, a fim se discernir as suas relações no espaço e no tempo e, usando-se de tais dispositivos, que produzam especulações que enriquecerão a compreensão das práticas. Esse conjunto de conceitos sensibilizadores propostos tem vinculação direta com as teorizações da prática, explicitadas no decorrer da obra de Nicolini (2012).

Esses conceitos sensibilizadores focam no "dizendo e fazendo", na ordem interacional, no espaço e no tempo, nas ferramentas, nos artefatos e na mediação do trabalho, nas preocupações práticas, na tensão entre criatividade e normalidade e nos processos de legitimidade e estabilidade ${ }^{4}$ (NICOLINI, 2012). Esses conjuntos ecléticos de conceitos sensibilizadores permitem que "características de diferentes práticas e as suas associações venham à tona" (NICOLINI, 2012). Para tanto, o movimento de zoom através do qual Nicolini propõe-se a representar, a prática "é conseguida, de fato, trocando as lentes teóricas e arrastando conexões de acordo com um conjunto de hipóteses específicas" (NICOLINI, 2012, p. 239).

Portanto, ao explicar que "para estudar a prática, precisamos começar a nossa investigação pelo zoom em práticas", Nicolini (2012, p. 221) destaca que o objetivo do zoom in é trazer à tona as preocupações práticas que governam e afetam todos os praticantes. Já o objetivo do zoom out é de "documentar e representar a textura das conexões entre as [diversas/diferentes] práticas" (NICOLINI, 2012, p. 238). Assim, referindo-se a essa última forma de zoom, Nicolini (2012, p. 230)

\footnotetext{
${ }^{3}$ Assim como de uma base totalmente oposta a essa, já que a teoria das organizações, segundo ele, tornou-se também demasiadamente abstrata e distanciada das atividades concretas que se propunha a descrever.

${ }^{4}$ Ver tabela 9.1 em Nicolini (2012, p. 220). Nessa tabela, o autor apresenta um conjunto de conceitos sensibilizadores que contribuem para nortear sua proposta de investigação.
} 
escreve que o zoom out na textura da prática "requer que sigamos as conexões entre as práticas, observando como essas conexões podem vir a formar nexos ou redes".

\subsection{Implicações metodológicas para o estudo da prática}

Em um de seus mais recentes trabalhos, Nicolini e Monteiro (2017) afirmam que as práticas precisam ser tematizadas e transformadas em objetos de análise, a fim de serem examinadas como entidades (ou seja, alguma coisa que existe). Porém, também alertam que as representações podem revelar algo em primeiro plano e ocultar outros. Assim, representar as práticas com a ideia de que elas podem simplesmente ser observadas e, de forma neutra, narradas, é assinar um projeto que pode vir a ser considerado como ideológico ou então, de certa maneira, limitado.

Por isso, os autores deixam claro que a lição metodológica é que, em vez de se procurar as razões do comportamento (organizacional ou social) dentro das pessoas, a abordagem da prática impele-nos a olhar para as relações, para como os sistemas de ações são atados conjuntamente e o que isso implica em termos de agência, significado e empowerment. Em vez de explicar a regularidade em termos de hábitos mentais ou rotinas externalizadas, a abordagem das práticas pergunta como esses são obtidos e mantidos, como os indivíduos participam na perpetuação ou na interrupção do comportamento e como os cursos rotinizados de ações são atados e mantidos juntos por outras ações rotinizadas ou objetos (ou por uma combinação de ambos) (NICOLINI; MONTEIRO, 2017).

É por essa razão que, primeiramente, Nicolini (2012) e, posteriormente Nicolini e Monteiro (2017) e Nicolini (2017), referem-se à abordagem da prática como um pacote de teoria-método. No trabalho conjunto de Nicolini e Monteiro, quatro desses pacotes, ou seja, quatro formas de se investigar as questões organizacionais, são citados. São eles: a) a abordagem situacional (dirigindose à realização local, à produção e à reprodução de práticas); b) a abordagem genealógica (que investiga a vida natural de práticas); c) a abordagem configuracional (que explora a forma como as práticas são atadas conjuntamente em configurações, examinando sua natureza trans-localizada) e d) a abordagem dialética (que se concentra em como tensão, contradições e desequilíbrios de poder produzidos por práticas mantêm-se em fluxo constante). Tais abordagens representam formas alternativas para que se "praxeologise" a organização e, uma vez alinhadas com o ecletismo, cobrem as principais estratégias utilizadas pelos teóricos da prática.

\subsection{Nicolini: Revelando a Natureza de sua Investigação Social}

Após a análise da principal obra do autor, assim como de outros escritos que caminham em direção a uma proposta do estudo das práticas, percebe-se que, efetivamente, Nicolini não chega a propor uma teoria, mas bases de uma "teoria" fundamentada. Para Takahashi (2013), a teoria fundamentada em dados visa desenvolver teorias a partir de conceitos e relações coletados, ao invés de utilizar modelos predeterminados, compreendendo a realidade a partir do conhecimento, sentido ou significado que certo contexto ou objeto tem para as pessoas.

A abordagem das práticas pergunta: como os indivíduos participam na perpetuação ou na interrupção de comportamentos? Como os cursos rotinizados de ações são atados e mantidos 
juntos por outras ações rotinizadas ou objetos? Dessa maneira, olhar é desvendar os processos de constituição da realidade social. Por isso que, na medida em que se utiliza um conjunto de teorias, mas não traz consigo suas ontologias, tampouco epistemologias, não se age de forma incoerente, pois delas apenas são trazidos conceitos sensibilizadores. Dado que a boa ciência é generativa e não eliminativista, efetivamente, está criando-se as bases para uma teoria fundamentada de base qualitativa, que não busca generalizações nem leis gerais, como buscam as teorias funcionalistas. Mas, busca-se o singular, o particular, com toda sua complexidade.

É por isso que Nicolini afirma que a abordagem da prática é um esforço para tornar o mundo mais rico em significado, na tentativa de explorar tanto as semelhanças quanto as diferenças das dimensões da prática sugeridas pelas teorias que revisou, propondo o que denominou de abordagem toolkit, ou seja, um conjunto de ferramentas que nos sensibiliza a olhar o empírico, as práticas cotidianas. Sua escolha ontológica é um reconhecimento da primazia da prática nas questões sociais, bem como a adoção da ideia de que as práticas (de uma forma ou de outra) são fundamentais para a produção, reprodução e transformação das questões sociais e organizacionais. Propondo uma ontologia plana que se traduz na crença de que as atividades humanas são concretas, não fazendo distinção entre nível micro e macro, as atividades são relacionais e os fenômenos sociais de pequena e grande escala são constituídos e experienciados no "micro".

Com base nessa ontologia, decorre sua proposta epistemológica, que é coerente com o ethos da prática, visto que propor uma teoria abstrata da prática seria uma incoerência. O que recomenda é que se estude a prática a partir do empírico. Dessa forma, apresenta um conjunto de conceitos sensibilizadores para uma aproximação com o empírico. As teorias da prática concebem a investigação social como baseada sistematicamente em evidências empíricas no esforço de compreensão das práticas, desdobrando suas relações. Elas questionam como tais práticas são realizadas e como as práticas conectadas fazem a diferença, perguntam por que é que o mundo resultante da união de várias práticas é do jeito que é e como e por que isso não é diferente (NICOLINI, 2012, p. 9).

\subsection{A abordagem da prática e a Grounded Theory: contribuições no estudo das práticas}

Parte-se do entendimento que a proposta de estudo das práticas sugerida por Davide Nicolini se alinha com os pressupostos da Grounded Theory (GT), pois se sabe, conforme as premissas dessa abordagem metodológica, que não se pode chegar ao empírico sem conceitos que nos sensibilizam a olhar a/para a realidade. A GT é uma ferramenta de desenvolvimento teórico local, enfatizando estudos locais que visam ao entendimento da situação. Nas palavras de Tarozzi (2011, p. 20), a GT "se coloca no estreito espaço que une teoria e realidade empírica". Por isso, Nicolini utiliza conceitos sensibilizadores provenientes das teorias da prática para iluminar a dinâmica das práticas, focando, assim, a explicação do fenômeno social de forma processual, sem perder de vista a natureza mundana da vida cotidiana e da natureza concreta e material das atividades com as quais estamos envolvidos (NICOLINI, 2012).

As teorias da prática são fundamentalmente projetos ontológicos no sentido de que tentam fornecer um novo vocabulário para descrever o mundo com "unidades de análise" específicas, isto 
é, as práticas. Parte-se do princípio que nomear, definir e exemplificar práticas já significa teorizálas. Tendo como principal princípio o fato de que

A proposta é estudar a prática empiricamente alternando sensibilidades teóricas. Adotando uma postura pluralista cautelosa e reflexiva. Entendendo como perfeitamente legítimo utilizar elementos comuns das teorias da prática como uma estratégia eclética, o que nos permite fornecer um relato mais espesso do mundo em que vivemos - uma aspiração comum a todos os autores examinados nos capítulos anteriores. Finalmente, esta abordagem agrega valor e oferece benefícios, uma vez que nos permite explorar os pontos fortes das diferentes teorias, a fim de obter uma melhor compreensão do nexo das práticas em que vivemos (NICOLINI, 2012, p. 213, tradução nossa).

Isso enfatiza ainda mais a nossa percepção de que a GT, apresentada por Tarozzi (2011) como uma teoria fundamentada em dados e que busca estar "apta à exploração, não de fenômenos estáticos, mas dos processos subjacentes a tais fenômenos e de suas dinâmicas" (TAROZZI, 2011, p. 22), é um método de pesquisa-empírica que pode contribuir com a compreensão das práticas organizacionais. Isso decorre, principalmente, do fato de que essa estratégia metodológica, como descrito por Tarozzi, "não se limita a recolher dados e analisá-los para verificar ou falsificar teorias preexistentes [...], mas constrói criativamente - e rigorosamente - uma teoria a partir dos dados, capaz de explicar os fenômenos pesquisados" (2011, p. 29). Esses aspectos também são ressaltados por Charmaz (2000) ao referir-se a GT como um método flexível e heurístico, mais do que apenas fórmulas de procedimentos. Assim, o alinhamento sugerido neste trabalho é de que a abordagem das práticas sugerida por Nicolini está alinhada com a Grounded Theory, uma vez que se manifesta como uma opção metodológica para o estudo das práticas não somente dentro das organizações, mas nos espaços sociais em que elas ocorrem. Isso ocorre, principalmente, porque o pacote teóricometodológico proposto faz uso do conjunto de conceitos sensibilizadores que convidam para a realização do zoom in e do zoom out nas práticas.

\section{CONSIDERAÇÕES FINAIS}

Após a análise do livro "Practice Theory, Work, and Organization" e demais publicações em 2017, pôde-se compreender que a proposta de Nicolini é um convite para abraçar de forma coerente uma versão sólida de uma abordagem da prática, com o pressuposto de que tal abordagem pode produzir radicalmente uma nova forma de compreensão das organizações e dos fenômenos organizacionais.

Considerando os aspectos desenvolvidos anteriormente, conclui-se que Nicolini rompe com as tradicionais formas de revelar os fenômenos sociais, organizacionais e do trabalho. Opõe-se a teorias abstratas e distanciadas das atividades concretas do cotidiano organizacional, afasta-se de uma ciência focada em proposições tautológicas, rompe-se com as perspectivas racionais, hipotético-dedutivas e estruturais-funcionalistas que enxergam as organizações através de modelos teóricos performativos da realidade. Assim, Nicoline opõe-se às velhas formas insustentáveis de teorização. Distancia-se de visões como a de uma ciência eliminativista (em oposição a uma ciência generativista), do exame da organização como entidades (organizações como coisa), das 
organizações apenas como discurso teórico, das perspectivas cognitivistas (que tentam explicar as organizações como decorrentes do cérebro ou da mente dos indivíduos), de um empirismo extremo (que entende que a realidade pode ser acessada ingenuamente, sem conceitos), de teorias textualistas (que reduzem a organização a um mundo de textos, sinais e comunicação), de teorias pós-modernas (nas quais o discurso é central) e de construções teóricas que compreendem a organização como meras trocas simbólicas.

Em contraposição, acredita-se que está no horizonte da proposta de Nicolini o lançamento das bases de uma "teoria" fundamentada, que possa vir a ser construída a partir da prática, do empírico, mantendo-se coerente com o ethos, com a lógica da prática. Nesse sentido, aproxima-se de uma ciência que visa a uma compreensão mais rica do mundo, de um mundo mais rico de significados, plural, enquanto um fenômeno complexo. Aproxima-se do empírico a partir de conceitos sensibilizadores de teorias contemporâneas da prática, que ajudam a revelar a realidade social.

A preocupação de Nicolini em estar sendo incoerente com os fundamentos ontológicos, epistemológicos e metodológicos ao propor uma abordagem múltipla, eclética comparada às teorias contemporâneas é compreensível e se justifica porque o que ele deduz das teorias são apenas conceitos sensibilizadores que utiliza para revelar as nuances das práticas e das redes que constituem a realidade dos fenômenos sociais e organizacionais. Assim, tal preocupação não é incoerente.

Por fim, corroborando com a visão de Schatzki (2002), Nicolini (2012) acredita que propor um "pacote de teorias e métodos" sob uma ontologia plana e relacional trará uma nova sensibilidade direcionada aos objetos de pesquisa, revelando uma nova visão das questões organizacionais. Como se afirma aqui, cria uma arena na qual a sua proposta de uma abordagem para o estudo das práticas inspira a utilização conjunta de métodos conhecidos e já utilizados nas investigações sociais, como a Grounded Theory. Sugestões da adoção de técnicas de pesquisas, como em Pimentel e Nogueira (2018), já caminham nessa direção, porém, é preciso ir além ao utilizarmos outros recursos como os que a GT proporciona. E, é nesse sentido que, como sugestão de pesquisas futuras, recomenda-se, neste ensaio teórico, que sejam realizadas investigações que avancem na reflexão teórica no processo de produção do conhecimento que enfoquem o estudo das práticas com a utilização do toolkit, sugerido por Nicolini, principalmente no que diz respeito aos conceitos sensibilizadores, oriundos de diferentes (mas complementares) perspectivas.

\section{REFERÊNCIAS}

CHARMAZ, K. (2000). Grounded theory: objectivist and constructivist methods. In: DENZIN, N. K.; LINCON, Y. S. (Eds.). Handbook of qualitative research. 2 ed. Thousand Oaks, CA: Sage Publications Inc., 509$535 \mathrm{p}$.

EMIRBAYER, M. (1997). Manifesto for a relational sociology. American Journal of Sociology, v. 103, n. 2, 281$317 \mathrm{p}$.

HUI, A.; SCHATZKI, T.; SHOVE, E. (2017). The nexus of practices: connections, constellations and practitioners. New York: Routledge. 
HUTCHINS, E. (1995). Cognition in the Wild. Cambridge, MA: MIT Press.

LATOUR, B. (2005). Reassembling the social: an introduction to actor-network-theory. Oxford: Oxford University Press.

LLEWELLYN, N. (2008). Organization in actual episodes of work: Harvey Sacks and organization studies. Organization Studies, v.29, n.5, 763-791 p.

NICOLINI, D. (2012). Practice theory, work, and organization: An introduction. 1. ed. Oxford: University Press.

NICOLINI, D. (2017). Is small the only beautiful? Making sense of 'large phenomena' from a practice-based perspective. In: HUI, A.; SCHATZKI, T.; SHOVE, E. (Eds.). The nexus of practices: connections, constellations and practitioners. New York: Routledge.

NICOLINI, D.; MONTEIRO, P. (2017). The practice approach: for a praxelogy of organizational and management studies. In: LANGLEY, A.; TSOUKAS, H. (Eds.) The SAGE Handbook of Process Organization Studies. London: Sage Publications.

PIMENTEL, R.; NOGUEIRA, E. E. S. (2018). Estudos Baseados na Prática: Possibilidades Metodológicas para Pesquisas em Estudos Organizacionais. Revista Organizações \& Sociedade, v. 25, n. 86, p. 350370.

SCHATZKI, T. R. (2002). The site of the social: A philosophical account of the constitution of social life and change. University Park, PA: Pennsylvania State University Press.

SOUZA, E. C. L. de; FENILI, R. R. (2016). O estudo da cultura organizacional por meio das práticas: uma proposta à luz do legado de Bourdieu. Cad. EBAPE.BR, Rio de Janeiro, v.14, n.4, 872-890 p.

TAKAHASHI, A. R. W. (Org.) (2013). Pesquisa Qualitativa em Administração: Fundamentos, Métodos e Usos no Brasil. São Paulo: Atlas.

TAROZZI, M. (2011). O que é Grounded Theory: metodologia de pesquisa e de teoria fundamentada nos dados. Petropólis: Vozes.

WEICK, K. E. (1979). The social psychology of organizing. 2nd ed. McGraw Hill. 